\title{
Study of the Isothermal Oxidation Process and Phase Transformations in B2-(Ni,Pt)A1/RENE-N5 System
}

\author{
Luis Alberto Cáceres-Díaz ${ }^{1}$, Juan Manuel Alvarado-Orozco ${ }^{2}$, Haidee Ruiz-Luna ${ }^{3}$, \\ John Edison García-Herrera ${ }^{1}$, Alma Gabriela Mora-García ${ }^{1}$, Gerardo Trápaga-Martínez ${ }^{1,4}$, \\ Raymundo Arroyave ${ }^{5}$ and Juan Muñoz-Saldaña ${ }^{1,6, *}$ \\ 1 Centro de Investigación y de Estudios Avanzados del IPN, Unidad Querétaro, \\ Libramiento Norponiente 2000, Real de Juriquilla, 76230 Querétaro, Mexico; \\ lcaceres@cinvestav.mx (L.A.C.-D.); johngarcia@cinvestav.mx (J.E.G.-H.); \\ almamora@cinvestav.mx (A.G.M.-G.); gerardo.trapaga@ciateq.mx (G.T.-M.) \\ 2 Centro de Ingeniería Avanzada y Desarrollo Industrial, CIDESI-Querétaro, Av. Pie de la Cuesta No. 702, \\ 76125 Santiago de Querétaro, Mexico; juan.alvarado@cidesi.edu.mx \\ 3 CONACYT-Universidad Autónoma de Zacatecas, Av. Ramón López Velarde 801, 98000 Centro Zacatecas, \\ Mexico; hruizlu@conacyt.mx \\ 4 Centro de Tecnología Avanzada, CIATEQ A.C.-San Agustín del Retablo 150, Constituyentes Fovissste, \\ 76150 Querétaro, Mexico \\ 5 Materials Science and Engineering Department, Texas A \& M University, College Station, TX 77843, USA; \\ rarroyave@tamu.edu \\ 6 German Aerospace Center (DLR), Institute of Materials Research, D-51170 Cologne, Germany \\ * Correspondence: jmunoz@cinvestav.mx; Tel.: +52-442-211-9924
}

Academic Editor: Hugo Lopez

Received: 8 June 2016; Accepted: 20 August 2016; Published: 1 September 2016

\begin{abstract}
Changes in composition, crystal structure and phase transformations of $\mathrm{B} 2-(\mathrm{Ni}, \mathrm{Pt}) \mathrm{Al}$ coatings upon isothermal oxidation experiments (natural and scale free oxidation) at $1100{ }^{\circ} \mathrm{C}$, as a function of time beyond their martensitic transformation, are reported. Specifically, the analysis of lattice parameter and composition are performed to identify changes in the $\mathrm{B} 2-(\mathrm{Ni}, \mathrm{Pt}) \mathrm{Al}$ phase upon the chemically-driven $\mathrm{L}_{0}-(\mathrm{Ni}, \mathrm{Pt}) \mathrm{Al}$ and $\mathrm{L}_{2}-(\mathrm{Ni}, \mathrm{Pt})_{3} \mathrm{Al}$ transformations. The $\mathrm{B} 2-(\mathrm{Ni}, \mathrm{Pt}) \mathrm{Al}$ phase was found to disorder and transform the martensite during the heat treatments for both oxidation experiments at approximately 36.3 and 40.9 at. \% of $\mathrm{Al}, 47.7$ and 42.9 at. $\%$ of Ni, 6.2 and 8.5 at. \% of $\mathrm{Pt}, 4.2$ and 2.9 at. \% of $\mathrm{Cr}$ and 4.4 and 3.8 at. \% of $\mathrm{Co}$. The lattice constant and the long-range order parameter of the $\mathrm{B} 2-(\mathrm{Ni}, \mathrm{Pt}) \mathrm{Al}$ phase decreased linearly as a function of the elemental content irrespective of the nature of the oxidation experiments.
\end{abstract}

Keywords: $\mathrm{B} 2-(\mathrm{Ni}, \mathrm{Pt}) \mathrm{Al}$ bond coatings; oxidation; martensitic transformation; crystal structure

\section{Introduction}

B2-(Ni,Pt)Al intermetallics are widely used as bond coats (BC) in Thermal Barrier Coating systems (TBCs) for aeronautic applications due to their high temperature oxidation and corrosion resistance [1,2]. Such properties are achieved because these intermetallics serve as $\mathrm{Al}$ reservoirs for the formation of a Thermally Grown Oxide (TGO) $\alpha-\mathrm{Al}_{2} \mathrm{O}_{3}$ layer upon oxidation at high temperature. The formed alumina scale acts as a barrier for the diffusion [3,4] and is the bonding material between the superalloy (SA) and the ceramic top coat (TC). NiAl has a $\mathrm{CsCl}$ crystal structure and can be defined by the sublattice model proposed by Ansara et al. [5]. In their work, two sublattices are used to define the $\mathrm{NiAl}$ system; $\mathrm{Al}$ is located in the first sublattice, $\beta ; \mathrm{Ni}$ is located in the second sublattice, $\alpha$. In this system, variations from stoichiometry are addressed as $\mathrm{Ni}$ antisites in the Ni-rich region, and as $\mathrm{Ni}$ vacancies (Va) in the Al-rich region of the B2 phase, according to the triple point defects model defined 
by Pike et al. [6]. The mechanical and oxidation behavior of NiAl varies as the Al content deviates from the 50:50 composition until the Ni-rich phase is achieved, but also with additions of ternary elements such as $\mathrm{Cr}, \mathrm{Co}, \mathrm{Hf}, \mathrm{Fe}$, Mo, among others. In the present case, the Pt content in the B2-(Ni,Pt)Al coatings reduces the detrimental effect of sulfur impurities on the scale adherence, prevents the formation of voids at the scale interface and improves the oxidation resistance because it directly diminishes the chemical activity of Al [7]. In the B2 phase, Pt occupies the Ni sites and has a solubility limit of 42 at. \% [8,9]. Other elements, such as $\mathrm{Cr}$ and $\mathrm{Co}$, are present in the bond coat since they diffuse from the superalloy during the heat treatments or high temperature exposures. $\mathrm{Cr}$ and Co are known to improve the oxidation and corrosion resistance and are assumed to occupy the Al and Ni sites, respectively $[10,11]$.

On the other hand, the Al depletion during operation (cyclic thermal and isothermal exposure at high temperature) leads to changes in mechanical (Young modulus and other elastic constants [12]) structural (ordering and size of crystals [1,13]) thermodynamic (phase stability [14], enthalpy of formation, entropy [15]) and diffusion kinetics (mobility of atoms [16]) of the NiAl alloy, and subsequently affects the lifetime of the TBC system. A loss of stability of the B2 phase also leads to martensitic, or even gamma prime phase transformations, generating stresses in the coating beneath the oxide scale and consequently, leads to TBC failure. For instance, some reports suggest that the stress fields are the main intrinsic failure mechanisms of TBCs [4] because they contribute to the rumpling of the BC [4,17], although there has been some controversy about the role of the martensitic phase transformation on the failure of the TBCs [18]. The martensitic phase transformation in B2-(Ni,Pt)Al coatings has been studied elsewhere by XRD, SEM and in-situ TEM in samples with $28 \%$ and $100 \%$ of their Furnace Cycle Test (FCT) life. In these reports, changes in the crystal structure, such as volume fractions, linear and thermal strains, microstructure and their role in the development of internal stresses are presented and discussed [19,20]. Additionally, Glynn et al. [21] performed numerical simulations to study the effect of the thermal expansion coefficient on the stress and strains distributions of the bond coat during cooling-heating cycles; they concluded that elastic (heating) and inelastic (cooling) loadings of the bond coat develop a maximum tensile stress in the Top Coat.

The effect of ternary element additions on the nature and evolution of the martensitic transformation has also been previously reported. Pt additions, and other ternary elements such as $\mathrm{Co}$ and $\mathrm{Cr}$, present an influence on the martensitic transformation temperature. For instance, Kainuma et al. [22] showed that the start temperature of the martensitic transformation, $M_{S}$ increases with Pt or Co additions and decreases when $\mathrm{Cr}$, Mo and Fe are added to the B2-NiAl phase. These studies have been carried out either by performing atomistic and numerical simulations or in high temperature cycled samples that already contain the martensite phase. However, the effect of the heat treatments on the stability of $\mathrm{B} 2-(\mathrm{Ni}, \mathrm{Pt}) \mathrm{Al}$ phase and its disordering until transformation to $\mathrm{L}_{1}-(\mathrm{Ni}, \mathrm{Pt}) \mathrm{Al}$ phase has not previously been reported.

The present contribution focuses on the effect of the isothermal exposure at $1100{ }^{\circ} \mathrm{C}$ of B2-(Ni,Pt)Al bond coats deposited on RENE N5 superalloys on the chemical composition, structure and microstructure of the bond coat, as well as on the chemically-driven $\mathrm{B} 2 \leftrightarrow \mathrm{L}_{0}$ martensitic transformation. The oxidation experiments are designed to vary the diffusion rates so that the structural changes in the B2 phase, and early stages of the transformation to the martensite phase, are separately identified and linked to the local chemical content along the BC.

\section{Materials and Methods}

The samples used for the isothermal oxidation experiments were coupons of $25 \mathrm{~mm}$ diameter and $3 \mathrm{~mm}$ thickness, provided by GE-Aircraft Engines-Cincinnati, $\mathrm{OH}$, USA. The coupons are composed of a low-activity B2-(Ni,Pt)Al bond coat on a RENE N5 superalloy. In this process, a Pt layer is electrolytically deposited over the substrate, whereas the $\mathrm{Al}$ is provided by a chemical vapor deposition process (CVD) and finally, the nickel required to form the B2 phase diffuses from the SA through vacuum heat treatments $[2,23]$. 
Two types of isothermal oxidation experiments were conducted in order to identify structural changes of the coatings related to the composition variations, regarding the possible effects of thermal and mechanical stresses as the alumina scale grows. Both experiments were conducted at $1100{ }^{\circ} \mathrm{C}$ in a single zone tube furnace (GSL-1100X, MTI Corporation, Richmond, CA, USA) in air $\left(p \mathrm{O}_{2} \sim 0.21 \mathrm{~atm}\right)$, varying the growth conditions of the scale, as follows: In the first case, eight specimens were oxidized as a function of time for $0-18 \mathrm{~h}$ in $3 \mathrm{~h}$ intervals. This experiment stands for a regular diffusion-controlled oxidation process, where $\mathrm{Al}$ selectively oxidizes to form alumina $\left(\mathrm{Al}_{2} \mathrm{O}_{3}\right)[24,25]$ at the surface. Since $\mathrm{Al}$ depletes in the bond coat, following the natural diffusion process controlled by the $\mathrm{pO}_{2}$ present at the metal-scale interface, this first case has been called Natural Oxidation (hereafter NO) experiments. On the contrary, the second type of experiment is called Scale-Free Oxidation (hereafter SFO) experiments because it corresponds to isothermal oxidation keeping the same $p \mathrm{O}_{2}(0.21 \mathrm{~atm})$ with a minimum presence of $\mathrm{Al}_{2} \mathrm{O}_{3}$ scale at the surface. One sample was used throughout the SFO experiment and exposed to high temperature for $5 \mathrm{~min}$ intervals for a total of $110 \mathrm{~min}$. The thin layer of alumina grown after every 5 min of exposure was removed mechanically with $\mathrm{SiC}$ paper, and the sample was exposed again to high temperature for $5 \mathrm{~min}$. This process was repeated until $110 \mathrm{~min}$ of exposure of the samples was completed. The TGO scale was removed in $5 \mathrm{~min}$ intervals to increase, for instance, the $\mathrm{Al}$ depletion rate in order to address its effect on the crystal structure of the intermetallic.

For comparative purposes, the units of time for NO and SFO experiments are unified to hours in Figures 2, 4 and 5. All samples were cooled down from $1100{ }^{\circ} \mathrm{C}$ to room temperature (RT) with a constant cooling rate $\left(100{ }^{\circ} \mathrm{C} / \mathrm{min}\right)$. Characterization of samples was also all performed at RT. It is well known that metallographic polishing introduces mechanical stresses and distorts the B2 lattice shadowing the structural characterization of the coating. To avoid this effect, the crystal structure of the bond coat is first characterized after every exposure to high temperature, then the alumina scale is removed by metallographic polishing and characterized in terms of chemical content and microstructure.

The structural properties of the coatings are studied by X-ray diffraction (XRD) using a diffractometer (Dmax2100, Rigaku, Tokyo, Japan) with $\mathrm{Cu}-\mathrm{K} \alpha$ radiation. All samples, irrespective of the oxidation process, are characterized before the oxidation treatments and right after every exposure to high temperature. The lattice parameter (a) of the B2 phase, as a function of oxidation time, is obtained using Bragg's law and applying Bradley and Jay's extrapolation [26]. Additionally, the long-range order parameter, $S$, is calculated using the following equation [27]:

$$
S=\sqrt{\frac{\frac{I_{S_{\_} o b s}}{I_{F_{-} o b s}}}{\frac{I_{L_{\_} r e f}}{I_{F_{-} r e f}}}}
$$

where $I$ is the relative intensity of the peaks of the B2 phase. The subscripts correspond to the contributions of the superlattice $(S L)$ and fundamental $(F)$ peaks of the thermally treated $(o b s)$ and "reference" (ref) samples. The "as-received" sample for the NO and SFO experiments are used as the reference condition, since no crystallographic information JCPDS (Joint Committee on Powder Diffraction Standards) files are available for the B2-(Ni,Pt)Al phase. The determination of $S$ is performed for those XRD patterns that allowed a reliable measurement of the superlattice/fundamental peaks ratio. This corresponds to the experiments from 0 to $1.25 \mathrm{~h}$ for SFO and from 0 to $12 \mathrm{~h}$ for NO oxidation experiments. After those times, superlattice peaks are not observed.

As mentioned before, after each XRD measurement, the samples were polished in order to remove the alumina scale (oxidation product), and the microstructure of the surface is studied by scanning electron microscopy (SEM) using a XL30 (Philips, Eindhoven, The Netherlands) with an incidence energy of $15 \mathrm{keV}$ and a working distance of $10 \mathrm{~mm}$. The microstructural details are revealed by etching the surface of the samples with an $\mathrm{HCl} / \mathrm{HNO}_{3}$ solution in a volume ratio of 5:1. The etching is carried out by dipping the sample 5 times for $5 \mathrm{~s}$. This procedure was defined after several procedures in dummy samples to avoid excessive sample etching and/or pitting. The chemical content on the surface 
of the samples is measured by using Energy Dispersive X-ray spectroscopy (EDS) with the Philips, XL30, Eindhoven, The Netherlands and verified in some samples by electron probe microanalysis (JXA-8530F, JEOL, Tokio, Japan). The incidence energy was $20 \mathrm{keV}$ and the working distance was $11 \mathrm{~mm}$. Diffusing elements from the SA (Cr, Co, W, Ta, Mo and Re) were identified in the bond coat besides the $\mathrm{Ni}, \mathrm{Al}$ and $\mathrm{Pt}$, but only $\mathrm{Ni}, \mathrm{Al}, \mathrm{Pt}, \mathrm{Cr}$, and $\mathrm{Co}$ are considered in the analysis because they belong to the bond coat as solid solution substitutional atoms and also have high solubility in the B2 phase. Other elements such as W, Ta, Mo, and Re that diffuse from the superalloy are heterogeneously distributed either in the BC or in a so-called interdiffusion zone (IDZ); they are not considered in the scope of this work and further work has to be done to address their effect on the properties of $\mathrm{B} 2-(\mathrm{Ni}, \mathrm{Pt}) \mathrm{Al}$ coatings.

\section{Results}

Figure 1 shows the composition of $\mathrm{Ni}, \mathrm{Al}, \mathrm{Pt}, \mathrm{Cr}$ and $\mathrm{Co}$ along the cross section of the as-received $\mathrm{B} 2-(\mathrm{Ni}, \mathrm{Pt}) \mathrm{Al}$ coatings used for the $\mathrm{NO}$ and SFO experiments, as a function of the distance from the surface covering the bond coat, the Interdiffusion Zone (IDZ) and the last $40 \mu \mathrm{m}$ belongs to the superalloy. The major constituent elements in the BC (Al, Ni and Pt) varied almost linearly from 51.5, 37.5 and 9.0 at. \% to 34.2, 44.2 and 3.7 at. \%, respectively. A slight increase in Pt is observed on the first $13 \mu \mathrm{m}$ of the BC and later decreased to 0 at the IDZ/SA interface. Co and Cr are also measured in the $\mathrm{BC}$ and vary from 1 and 0.3 at. \% to 7 and 7 at. \%, respectively. The IDZ showed heterogeneous concentrations of $\mathrm{Ni}, \mathrm{Al}, \mathrm{Pt}, \mathrm{Co}$ and $\mathrm{Cr}$ distributed in $\gamma$ and $\gamma^{\prime}$ phases, as well as $\mu$ precipitates $[7,28]$. Minor content elements, mainly allocated in the IDZ such as W, Re, Ta, Mo (not shown in Figure 1) are also present even in the BC but are not considered in the analysis. Finally, the chemical content of the SA is in agreement with that previously reported in the literature [29] and showed a constant behavior along the measured section.

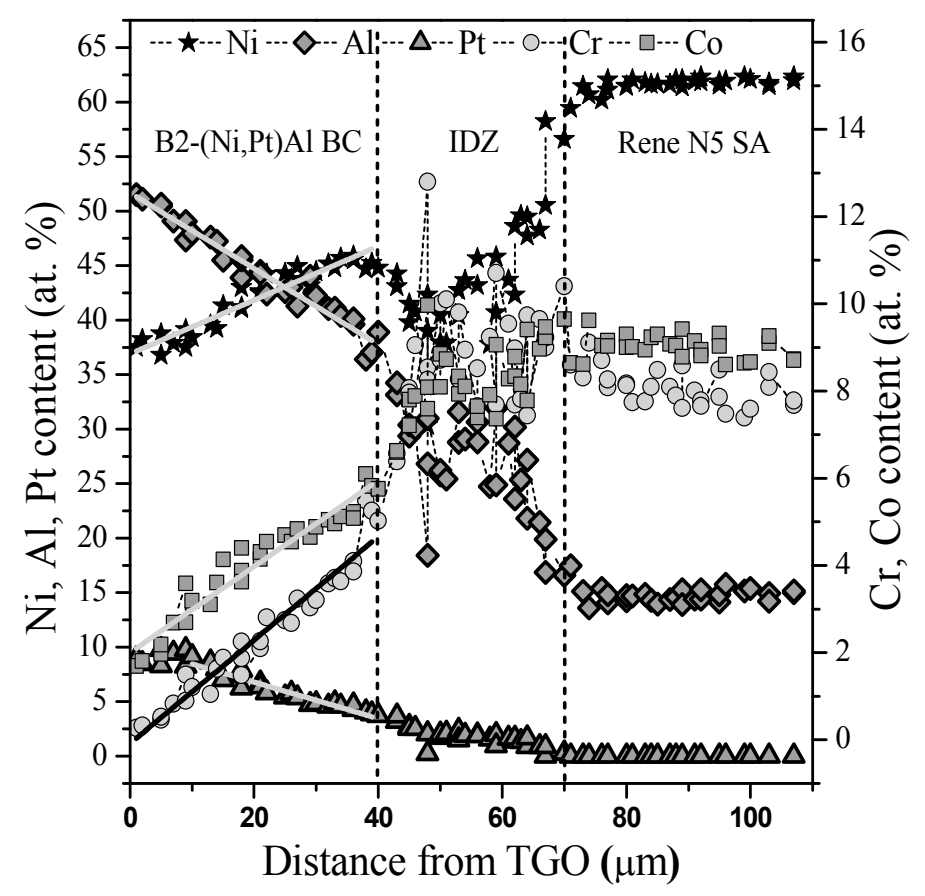

Figure 1. Concentration profiles of a cross section reference sample obtained from EPMA, starting from the BC surface, through the IDZ zone up to the SA.

Changes in the crystal structure as a function of oxidation time are obtained by XRD. The B2 crystal structure of the as-received coatings is unambiguously identified in Figure 2a,b for NO and SFO experiments, respectively, through the appearance of its fundamental and superlattice peaks. 
The fundamental (110), (200) and (211), and the superlattice (100), (111) and (210) diffraction peaks of the $\mathrm{B} 2-(\mathrm{Ni}, \mathrm{Pt}) \mathrm{Al}$ phase are clearly identified in the as-received samples for both experiments. The fundamental peaks correspond to those diffraction planes that satisfy the selection rules for BCC lattices $(h+k+l=e v e n)$, and superlattice peaks correspond to the peaks that do not satisfy such rules. Since the martensite phase has a Face Centered Tetragonal crystal structure, the fundamental peaks correspond to the diffraction planes that satisfy the selection rules for FCC lattices (unmixed $h+k+l$ ), and superlattice for those that do not apply to these selection rules [27]. The $\mathrm{Al}_{2} \mathrm{Pt}$ phase is also identified in some of the samples in the as-received conditions for the $\mathrm{NO}$ experiments and is represented with the symbol $\mathrm{V}$. As expected, $\alpha-\mathrm{Al}_{2} \mathrm{O}_{3}$ is also observed in all the samples exposed to $\mathrm{NO}$ experiments whereas it is weakly detected in SFO samples. A monotonic shifting to higher angles and a decrease in the superlattice peaks' intensity are evidence of the structural changes taking place during the $\mathrm{NO}$ and $\mathrm{SFO}$ experiments. The martensite $\mathrm{L} 1_{0}-(\mathrm{Ni}, \mathrm{Pt}) \mathrm{Al}$ phase is clearly identified after $6 \mathrm{~h}$ and $0.92 \mathrm{~h}$ for the NO and SFO samples respectively. The criterion to define the onset time of $\mathrm{L} 1_{0}$-phase formation is based on the appearance of the fundamental (111) peak at 43.3 degrees of $2 \theta$. Superlattice peaks of the B2 phase are not observed after $15 \mathrm{~h}$ for NO and $1.83 \mathrm{~h}$ for SFO. However, small fundamental peaks indicate the presence of a partially disordered B2 phase. The gamma prime $\mathrm{L}_{2}-(\mathrm{Ni}, \mathrm{Pt})_{3} \mathrm{Al}$ phase is also observed in the experiments after $18 \mathrm{~h}$ and $1.83 \mathrm{~h}$ for $\mathrm{NO}$ and $\mathrm{SFO}$, respectively.

In the region of the mixture of phases, the martensite exhibited both superlattice and fundamental peaks during all the periods of high temperature exposure, while the austenite (B2 phase) partially decreased the superlattice peaks until they disappeared at $15 \mathrm{~h}$ and $1.83 \mathrm{~h}$ of NO and SFO experiments. It is important to remark that the superlattice peaks result after the contribution of the scattered X-rays by the atoms located in the $\alpha$ and $\beta$ sublattices of the B2 phase, and therefore they depend on the difference in the Atomic Scattering factors (ASF) of the elements. Thus, the superlattice peaks allow to identify if the $\mathrm{Ni}$ and $\mathrm{Al}$ atoms occupy their corresponding sublattices in the B2-NiAl alloy or, if they are randomly arranged, promoting a disordered state of this intermetallic [27].

The decrease of the austenite superlattice peaks shows that this phase partially disorders as a function of the oxidation time and becomes completely disordered after $15 \mathrm{~h}$ and $1.25 \mathrm{~h}$ of NO and $\mathrm{SFO}$, while the martensite phase remains ordered as the oxidation time increases.

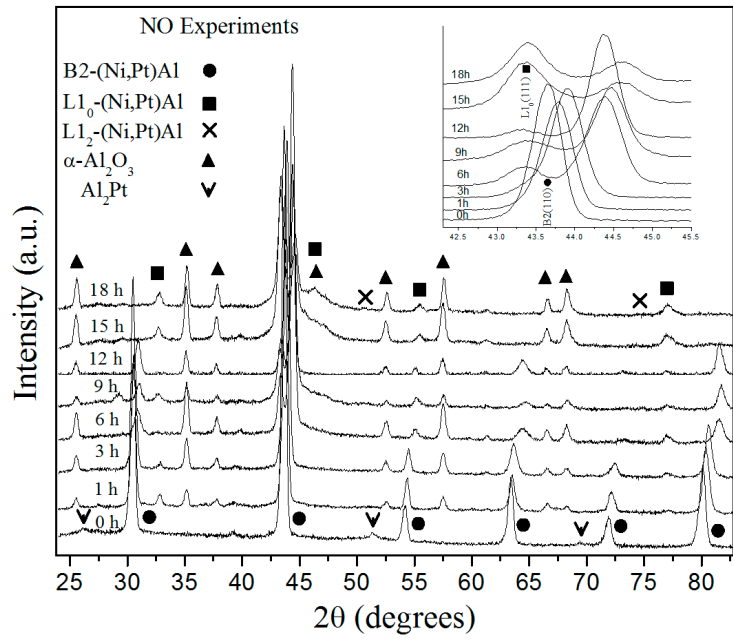

(a)

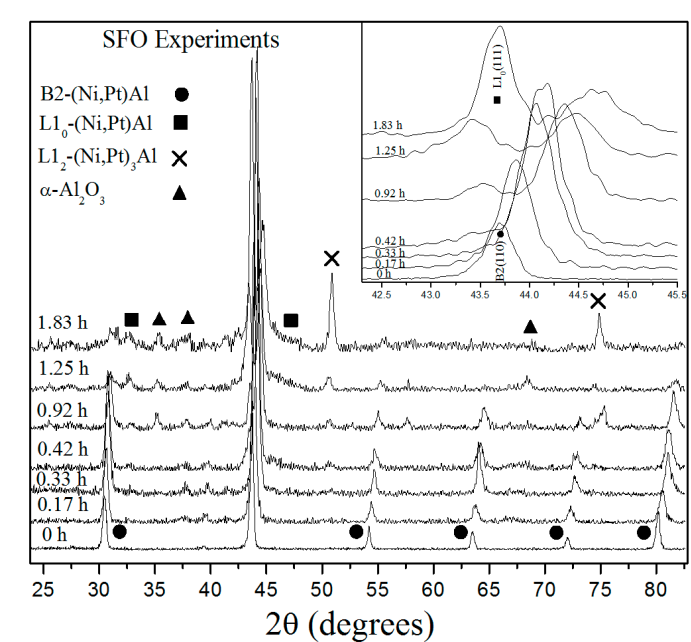

(b)

Figure 2. XRD patterns for samples processed by (a) natural oxidation for thermal exposure times of $0-18 \mathrm{~h}$ and (b) scale free oxidation for thermal exposure times of 0-110 $\mathrm{min}$. The inset is a magnified view which better shows the evolution of the $\mathrm{L} 1_{0}(111)$ and $\mathrm{B} 2$ (110) peaks. 
SEM micrographs of the microstructure of the NO samples in the as-received conditions, as well as those oxidized for $18 \mathrm{~h}$, are presented in Figure 3a,b, respectively. The expected B2 phase (previously identified by XRD) shows equiaxed grains with a heterogeneous size in the range between 3 and $6 \mu \mathrm{m}$. For the $18 \mathrm{~h}$ - NO sample, B2-(Ni,Pt)Al, $\mathrm{L}_{0}-(\mathrm{Ni}, \mathrm{Pt}) \mathrm{Al}$ and $\mathrm{L} 1_{2}-(\mathrm{Ni}, \mathrm{Pt})_{3} \mathrm{Al}$ phases are identified based on their morphology. Particularly, the $\mathrm{L}_{0}-(\mathrm{Ni}, \mathrm{Pt}) \mathrm{Al}$ phase is identified because the grains show the common habit planes of the martensite phase, which is the product of a diffusionless transformation of the B2 phase upon cooling [21]. This sample also shows a grain coarsening effect of both beta and the martensite grains (grain size between 8 and $12 \mu \mathrm{m}$ ).

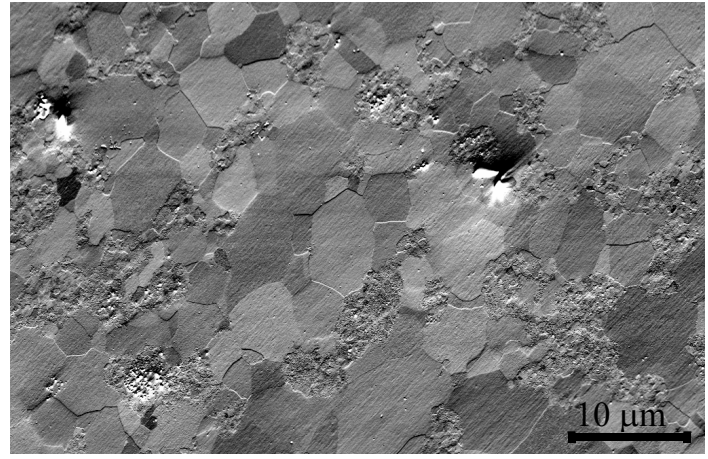

(a)

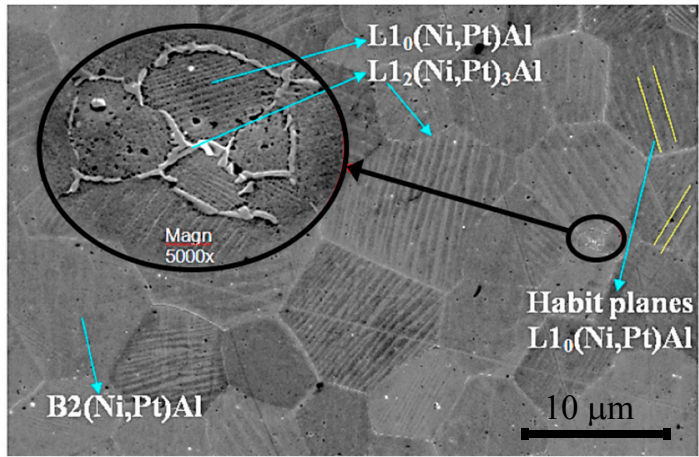

(b)

Figure 3. SEM micrographs of the bond coat surface (a) before and (b) after scale free oxidation for 110 min. $\mathrm{B} 2-(\mathrm{Ni}, \mathrm{Pt}) \mathrm{Al}, \mathrm{L1}_{0}-(\mathrm{Ni}, \mathrm{Pt}) \mathrm{Al}$ and $\mathrm{L1}_{2}-(\mathrm{Ni}, \mathrm{Pt})_{3} \mathrm{Al}$ phases are identified with arrows. The martensite phase is well identified in $(\mathbf{b})$ by its habit planes.

The pores observed in the grains in Figure $3 b$ are likely to be the result of either vacancy condensation (e.g., Kirkendall effect) and/or chemical etching attack during the metallographic sample preparation. Additionally, precipitates of $\gamma^{\prime}$ phase are observed in grain boundaries due to $\mathrm{Al}$ diffusion. This diffusion mechanism generates regions with a higher content of $\mathrm{Ni}$ and leads to the transformation to $\gamma^{\prime}(\mathrm{Ni}, \mathrm{Pt})_{3} \mathrm{Al}$ [23]. The identification of the $\gamma^{\prime}$ phase shows that the content of the coating exposed to $18 \mathrm{~h}$ is in the region of mixture of phases $\mathrm{B} 2+\mathrm{L}_{2}$, which correlates well to XRD measurements.

Figure 4 shows variations in composition from the sample surfaces exposed to both oxidation experiments. Particularly, Figure $4 \mathrm{a}(\mathrm{Ni}, \mathrm{Al})$ and $4 \mathrm{~b}(\mathrm{Pt}, \mathrm{Cr}, \mathrm{Co})$ show the values corresponding to the NO experiments and Figure $4 \mathrm{c}(\mathrm{Ni}, \mathrm{Al})$ and $4 \mathrm{~d}(\mathrm{Pt}, \mathrm{Cr}, \mathrm{Co})$ correspond to the $\mathrm{SFO}$ experiments.
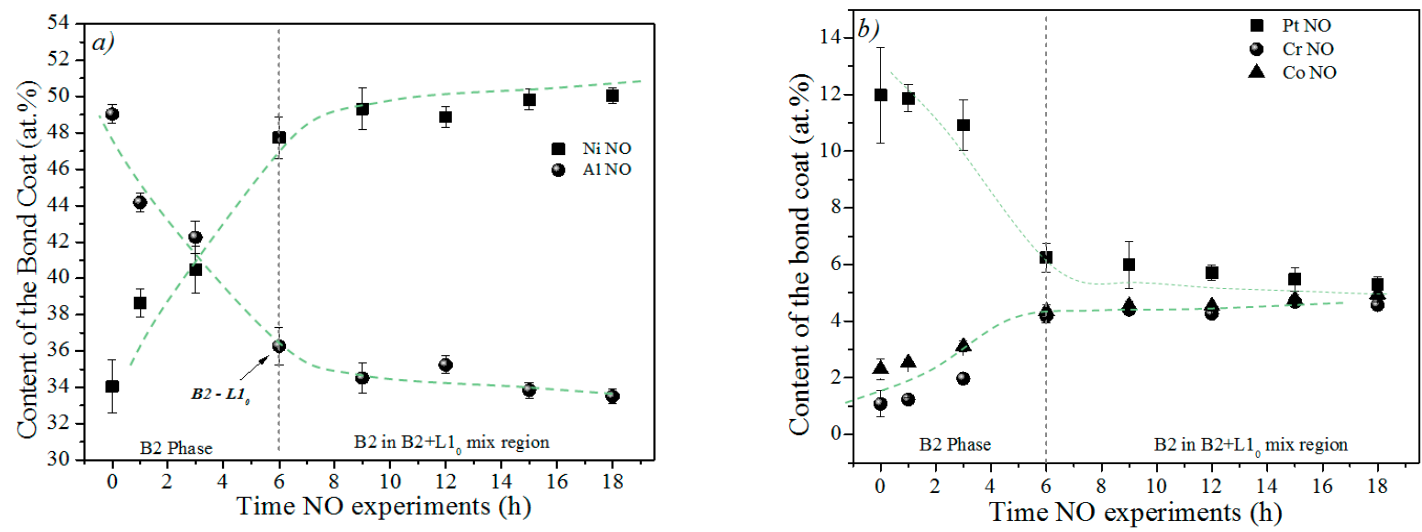

Figure 4. Cont. 

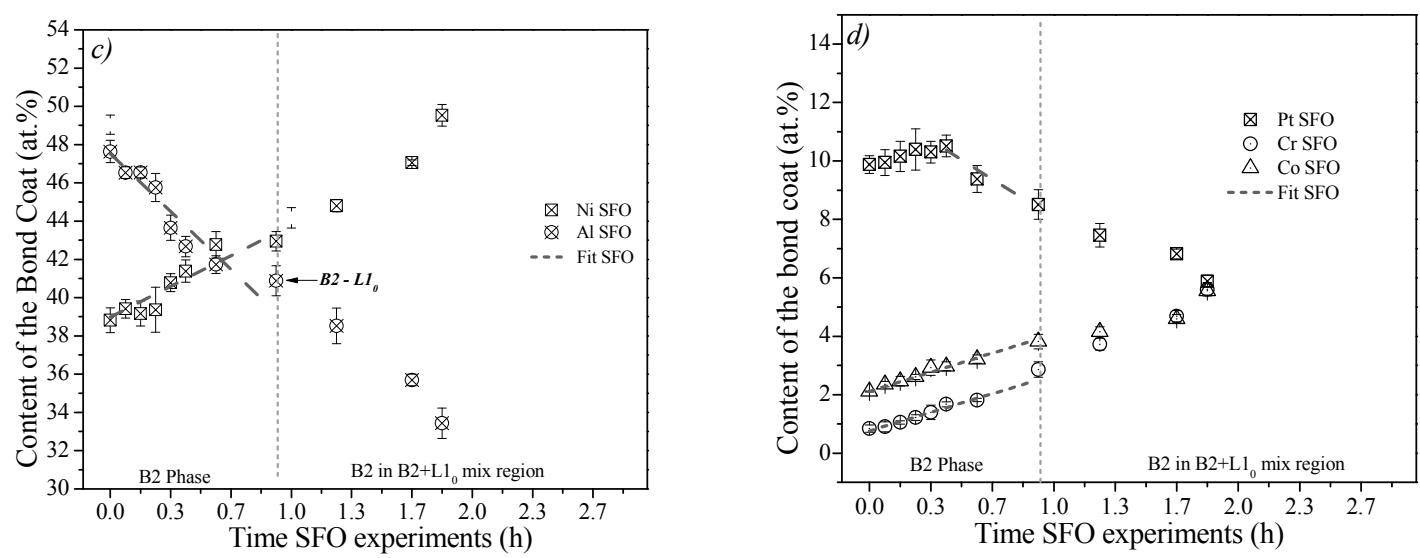

Figure 4. Variation in $\mathrm{Al}$ and $\mathrm{Ni}$ content as a function of (a) $\mathrm{NO}$ and (c) SFO heat treatment time. The martensitic transformation conditions are indicated at 36.9 at. \% $\mathrm{Al}$ after $6 \mathrm{~h}$ of thermal exposure and at 40.9 at. \% Al after $0.92 \mathrm{~h}$ of thermal exposure. Variation in $\mathrm{Pt}, \mathrm{Cr}$ and Co content as a function of (b) NO and (d) SFO heat treatment time.

The $\mathrm{Al}$ content decreased as a function of heat treatment time from 49.0 to 33.5 at. \% and from 47.6 to 33.4 at. \%, whereas the $\mathrm{Ni}$ increased from 34.0 to 50.0 at. \% and from 38.8 to 49.5 at. \% for NO and SFO, respectively (Figure $4 a, c$ ). The Pt content decreased from 12.0 to 5.3 at. $\%$ and from 9.9 to 5.9 at. \% for NO and SFO. In contrast, Co increased from 2.3 to 4.9 at. \% and from 2.1 at. \% to 5.6 at. \% for NO and SFO, respectively. Similarly, $\mathrm{Cr}$ content increased from 1.0 to 4.6 at. \% and from 0.8 to 5.6 at. \%.

For comparative purposes, the $\mathrm{X}$ axes are matched from the as-received $(0 \mathrm{~h})$ up to the onset of martensitic transformation. These conditions correspond to $6 \mathrm{~h}$ and $0.92 \mathrm{~h}$ for $\mathrm{NO}$ and SFO, respectively. This criterion applies for composition and lattice constant and long-range ordering from Figures 4 and 5.

From Figure $4 \mathrm{a}, \mathrm{b}$, a quasi-parabolic composition profile as a function of the oxidation time is observed for the NO experiments, whereas an almost linear profile is observed for the SFO experiments. For NO experiments, two regions of variation that are defined by the onset of the martensitic transformation are observed. The approximate ratio of the depletion rates in these regions are $10 \%, 12 \%, 14 \%, 15 \%$ and $7 \%$ for $\mathrm{Al}, \mathrm{Ni}, \mathrm{Pt}, \mathrm{Cr}$ and $\mathrm{Co}$, respectively.

Thus, from 0 to $6 \mathrm{~h}$, high depletion rates are observed for all the elements, keeping however the B2 composition; hereafter called B2 region, since it corresponds to the oxidation phenomena that occurs before the martensitic transformation. In the second region, the elements presented a lower depletion rate and are called " $\mathrm{B} 2+\mathrm{L} 1_{0}$ region" because they correspond to the zone where beta and martensite phase coexist at RT.

On the other hand, the composition of samples exposed to SFO experiments followed only one tendency in the diffusion processes during all the experiments, even after the martensitic transformation (Figure $4 \mathrm{~d}$ ).

\section{Discussion}

Considering the three major elements ( $\mathrm{Al}, \mathrm{Pt}$ and $\mathrm{Ni}$ as a balance), the composition of the as-received coating surface corresponds to the stoichiometric $\mathrm{B} 2-(\mathrm{Ni}, \mathrm{Pt}) \mathrm{Al}$ phase of the Al-Ni-Pt phase diagram (see Figure 1). A composition gradient is observed from the surface through the coating thickness moving to the $\mathrm{B} 2+\mathrm{L}_{2}$ region as it approaches the IDZ boundary [10]. The crystal structure from the surface of the as-received and heat-treated samples was verified by XRD (see Figure 2). As expected, during coating preparation both the $\mathrm{B} 2-(\mathrm{Ni}, \mathrm{Pt}) \mathrm{Al}$ and the underlying superalloy show interdiffusion processes leading to composition gradients with positive $(\mathrm{Ni}, \mathrm{Cr}, \mathrm{Co})$ or negative $(\mathrm{Al}$ and $\mathrm{Pt})$ trends $[2,23]$. 
The particular increase of $\mathrm{Pt}$ on the first $13 \mu \mathrm{m}$ of the BC causes inversely proportional changes in the Ni content. This behavior is because Pt has a preference for the Ni sites in the B2 crystal structure since the bond strength of AlPt is stronger than that of AlNi. As a consequence, Pt decreases the chemical activity of $\mathrm{Al}[1,7]$.

It is worth noting that the oxidation time does not represent a reliable variable to correlate the structural and chemical properties in both experiments because it changes according to specific oxidation conditions. Instead, physical and/or thermodynamic considerations, as well as the phase transformations that occur in the coating, must be taken into account. To do so, and as mentioned before, the experiments are compared in Figures 4 and 5 from $0 \mathrm{~h}$ to the onset of the martensitic transformation.

The NO and SFO experiments represent different oxidation kinetics. Nevertheless, the boundaries for the $\mathrm{B} 2 \rightarrow \mathrm{L1}_{0}$ martensitic transformation in the $\mathrm{NO}$ experiments are 36.3 at. \% $\mathrm{Al}, 6.2 \mathrm{at}$. \% $\mathrm{Pt}$, 4.2 at. $\% \mathrm{Cr}, 4.4$ at. $\% \mathrm{Co}$ and 47.7 at. \% Ni, and those for the SFO experiments are 40.9 at. \% $\mathrm{Al}$, 8.5 at. $\% \mathrm{Pt}, 2.9$ at. $\% \mathrm{Cr}, 3.8$ at. \% Co and 42.9 at. \% of Ni.

The increase of $\mathrm{Pt}$ during the first $0.42 \mathrm{~h}$ of SFO experiments (Figure $4 \mathrm{~d}$ ) seems to be associated with the fabrication process, since a similar trend is also observed in the as-coated sample, in which, as mentioned before, $\mathrm{Pt}$ increases during the first $13 \mu \mathrm{m}$ of the BC (see Figure 1).

Another non-expected increment of $\mathrm{Al}$ is observed in the sample exposed to $12 \mathrm{~h}$ of $\mathrm{NO}$ due to the presence of the $\mathrm{Al}_{2} \mathrm{Pt}$ phase. The characterization of all the specimens in the as-received conditions allowed the identification of the aforementioned phase in the samples that were later exposed to 0,3 and $12 \mathrm{~h}$. In this case, the $\mathrm{Al}_{2} \mathrm{Pt}$ phase dissolves, which increases the $\mathrm{Al}$ content of the coating.

Figure 5a,b show the lattice constant $a$ and long-range order parameter $S$ of the B2-(Ni,Pt)Al phase obtained from the analysis of the XRD patterns for the NO and SFO experiments as a function of the oxidation time. The lattice constant of the as-received sample is $2.932 \AA$, which is in turn $1.6 \%$ higher than that expected for the stoichiometric binary $\mathrm{NiAl}$ alloy. This increase is due to Pt-additions (12 at. \%) and is in agreement with results reported by Chen et al. [30]. In general, it is found that the lattice constant decreases as a function of the thermal exposure time and follows similar trends for $\mathrm{NO}$ and SFO experiments during the first stages of the oxidation.

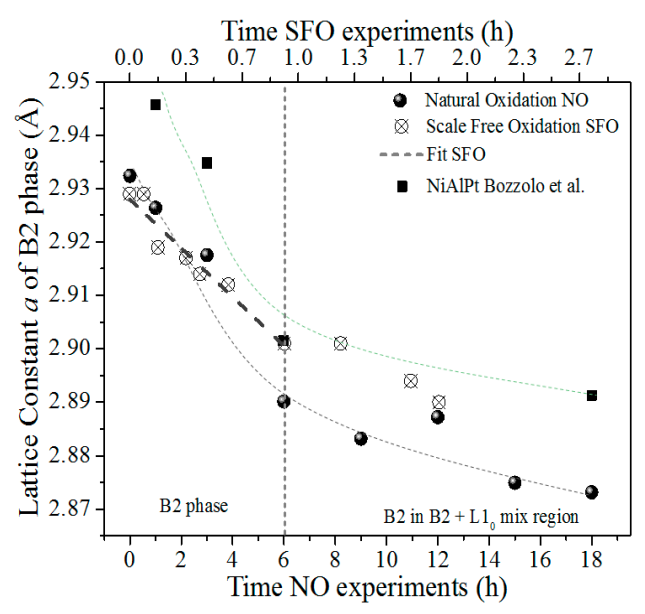

(a)

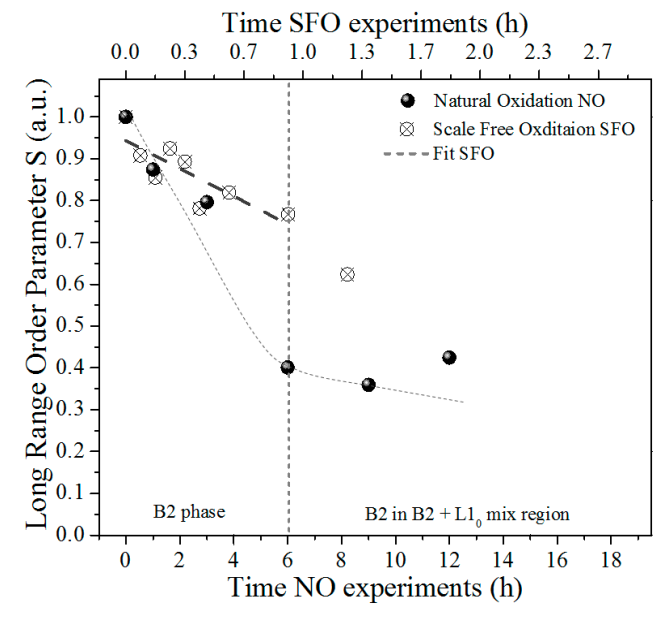

(b)

Figure 5. (a) Experimental and calculated lattice constant $a$ of the B2 phase for NO and SFO experiments; (b) Long range ordering $\mathrm{S}$ of the $\mathrm{B} 2$ phase as a function of the exposure time for natural and scale free oxidation experiments.

The coupled behavior between composition and lattice constant has already been studied by Bozzolo [13] and Pike [31] for the binary NiAl systems, which follows the Vergard's law for 
substitutional solid solution alloys. The contribution of other elements to the lattice constant of the B2 phase depends on its size and specific location in every sublattice, according to the structural triple point defects generated in this alloy [6]. Based on the sublattice model for NiAl by I. Ansara [5] and on the site preference models for $\mathrm{Pt}, \mathrm{Cr}$ and Co proposed by Jiang et al. $[8,12]$, the $\mathrm{B} 2-(\mathrm{Ni}, \mathrm{Pt}) \mathrm{Al} \mathrm{BC}$ can be represented by a two sublattice descriptions as $\mathrm{B} 2-(\mathrm{Ni}, \mathrm{Pt}, \mathrm{Co})(\mathrm{Al}, \mathrm{Cr}, \mathrm{Ni})$. Given that $\mathrm{Al}$ depletes during the oxidation, the studied system will remain in the Ni-rich alloy region, where no vacancies are expected and $\mathrm{Ni}$ antisites are considered. Additionally, $\mathrm{Pt}, \mathrm{Cr}$ and $\mathrm{Co}$ are taken as substitutional solid solution defects.

A detailed observation of the composition variations (Figure 4), $a$ and $S$ at the martensitic transformation boundary ( $6 \mathrm{~h} \mathrm{NO}$ and $0.92 \mathrm{~h} \mathrm{SFO})$, shows a direct relation between the $\mathrm{Al}$ and $\mathrm{Pt}$ contents and these structural parameters of the $\mathrm{B} 2-(\mathrm{Ni}, \mathrm{Pt}) \mathrm{Al}$ phase. Unlike the other elements, the higher Al content the higher $a$ and $S$ is observed. A similar behavior is observed at $12 \mathrm{~h}$ of oxidation in the NO experiment, where the effect of $\mathrm{Al}$ content on the $a$ and $S$ is probably due to the dissolution of the $\mathrm{Al}_{2} \mathrm{Pt}$ in the $\mathrm{B} 2$ phase at high temperature.

Del Grosso et al. [32] performed a theoretical calculation of the effects of $\mathrm{Pt}$ on the lattice constant of $\mathrm{NiAl}$ as a function of composition based on the Bozzolo-Ferrante-Smith method. For comparison, their results are plotted as squares in Figure $5 \mathrm{a}$ for 1, 3, 6 and $18 \mathrm{~h}$. The compositions for these times are normalized to the NiAlPt system and correspond to the simulated values by Del Grosso et al. Although the theoretically calculated $a$ values are higher than the experimental ones, there is a good agreement in their tendencies as a function of the oxidation time, which is proportional to the composition. Thus, changes in the crystal structure of $\mathrm{B} 2-(\mathrm{Ni}, \mathrm{Pt}) \mathrm{Al}$ coatings caused by the oxidation are prompt to be addressed through experimental and atomistic simulations approaches seeking a better understanding of their structural stability and phase transformations.

For instance, Sordelet et al. [33] studied the effects of $\mathrm{Pt}$ on the isothermal nature of the martensitic transformation of $\mathrm{NiAl}$ and found that $\mathrm{Pt}$ increases the start martensitic transformation temperature Ms. Complementary results are presented by Jiang et al., [34] based on Density Functional Theory calculations, and show that $\mathrm{Pt}$ additions decrease the shear $C^{\prime}$ and $\mathrm{C}_{44}$ moduli and thus destabilize the B2 phase. Additionally, the Al-Ni-Pt phase diagram reported by Hayashi et al. [10] proposes an extended region where the martensitic transformation may occur. Additions of 20 at. \% Pt move the $\mathrm{Al}$ boundary for transformation up to approximately 40 at. \% $\mathrm{Al}[33,35]$. These observations are directly associated with the present results because the coatings exposed to SFO experiments contain higher $\mathrm{Pt}$ content and transformed at higher $\mathrm{Al}$ contents than the values required for martensitic transformation in the binary $\mathrm{NiAl}$ (about 37 at. \%) alloy.

The behavior of $S$ is found to be in accordance with the chemical content changes in the bond coat, following the trends of $\mathrm{Al}$ depletion in every region. Although $S$ presents similar values for the $\mathrm{B} 2$ region, a significant difference is observed at the transformation boundary $(6 \mathrm{~h}$ for $\mathrm{NO}$ and $0.92 \mathrm{~h}$ for SFO) which is explained in terms of the chemical content on each sample, and their role contributing to the scattering of the X-rays depending on the site occupancy of the sublattices in the B2 structure [12]. As can be seen in Figure 4c,d, the sample exposed to $0.92 \mathrm{~h}$ contained more $\mathrm{Al}$ and $\mathrm{Pt}$ than the sample exposed to $6 \mathrm{~h}$ (Figure $4 \mathrm{a}, \mathrm{b}$ ) and consequently less Ni. No significant differences are observed for $\mathrm{Cr}$ and $\mathrm{Co}$ between both types of samples. Remembering that the B2 phase can be described by the 2 sublattice model, where $\mathrm{Pt}$ and Co occupy the Ni sublattice and $\mathrm{Cr}$ occupies the $\mathrm{Al}$ sublattice, six binary systems (B2-XAl and B2-XCr, X: Ni, Pt and $\mathrm{Co}$ ) can be compared to understand the role that the elemental composition of the alloy has on the superlattice peaks' intensity observed in the X-ray patterns. These peaks are a consequence of the difference in ASF in every sublattice and therefore define the long-range order parameter. Despite the simplicity of the binary models, these are useful to show the contributions of the elements to the superlattice peaks. For instance, the difference in ASF of the binary models at $2 \theta=30.9^{\circ}$ that correspond to the superlattice (100) peak are: $\mathrm{B} 2-\mathrm{PtAl} \rightarrow 44.86, \mathrm{~B} 2-\mathrm{PtCr} \rightarrow 38.57, \mathrm{~B} 2-\mathrm{NiAl} \rightarrow 8.97, \mathrm{~B} 2-\mathrm{CoAl} \rightarrow 8.28, \mathrm{~B} 2-\mathrm{NiCr} \rightarrow 2.68$ and $\mathrm{B} 2-\mathrm{CoCr} \rightarrow 1.99$. It is clearly observed that the larger differences correspond to the Pt containing alloys 
due to the higher electronic density of Pt. This analysis is in good agreement with the content of $\mathrm{Al}$ and $\mathrm{Pt}$ at the transformation boundary.

Thus, composition, lattice parameter, as well as for long-range ordering, all follow similar behaviors, showing two regions of variation before and after the martensitic transformation for NO experiments, and an almost linear decrease for SFO experiments.

Given that the oxidation time is not a physically meaningful independent variable, nor does it allow direct comparison of natural and scale free oxidation results, the lattice constant and long-range ordering parameter are plotted in Figure 6 versus the corresponding variable, as a function of the $\mathrm{Al}$ content for NO and SFO experiments, since it is the most representative contributor to the crystal structure properties and ordering. The oxidation process is shown by the expressions "Oxidation starts" for $0 \mathrm{~h}$ and "Oxidation ends" for $18 \mathrm{~h}$ and $1.83 \mathrm{~h}$ of $\mathrm{NO}$ and SFO, respectively. Data from the literature for the binary NiAl system is also represented in Figure 6 for comparative purposes. The values reported by Bozzolo et al. [36] correspond to first principles calculations performed in $\mathrm{B} 2-\mathrm{NiAl}$ and applying $\mathrm{Ni}$ antisite defects for compositions out of the stoichiometry, in order to maintain the B2 crystal structure.

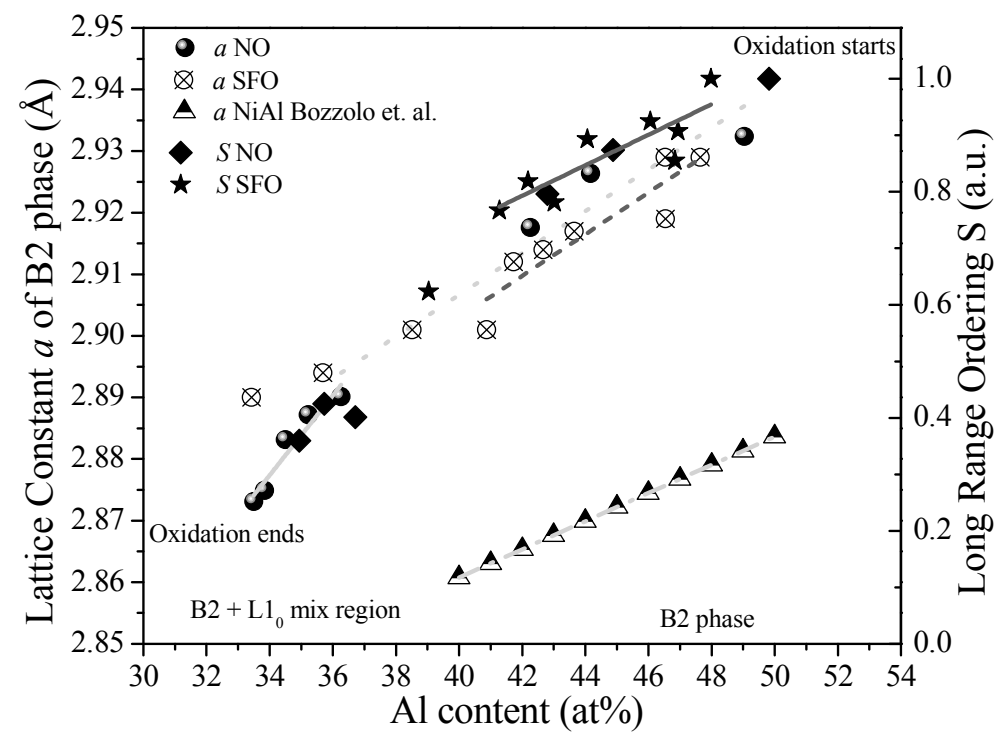

Figure 6. Variation of lattice constant as a function of $\mathrm{Al}$ content for $\mathrm{NO}$ and SFO experiments. Results of the analysis from a Binary (Bozzolo) and commercial systems are included.

The lattice constant of the $\mathrm{B} 2-(\mathrm{Ni}, \mathrm{Pt}) \mathrm{Al}$ phase shows a linear dependence with the $\mathrm{Al}$ content during the complete isothermal oxidation process, irrespective of the nature of the oxidation (NO or SFO). This behavior corresponds to substitutional solid solution alloys, where the elements are replaced by others following a model of hard spheres and where Vegard's law can be applied. Based on the slopes of the linear trends, we can see that the dependence of the lattice constant with $\mathrm{Al}$ content in the commercial coatings showed good agreement with the behavior of the simulated $\mathrm{NiAl}$ binary system. The dispersion of $a$ values and slight differences in the slopes from 40 to 50 at. $\% \mathrm{Al}$ are attributed to the change of $\mathrm{Pt}, \mathrm{Cr}$ and $\mathrm{Co}$ in the $\mathrm{Ni}$ and $\mathrm{Al}$ sublattices from the as-received conditions $(0 \mathrm{~h})$ to the transformation boundaries $(6 \mathrm{~h}$ and $0.92 \mathrm{~h})$. The difference in the lattice constant between the simulations and experiments is mainly due to the effect of Pt substitutions in the Ni site. These results are in agreement with the work reported by Chen et al. [30]. The effect of $\mathrm{Cr}$ and Co on the lattice constant are not expected to be determinant on the size of the unit cell because their atomic radiuses are similar to that of $\mathrm{Ni}$, and according to the triple point defect model and site preferences, they do not affect this parameter. 
The linear dependence of the lattice constant as a function of $\mathrm{Al}$ content in the region of mixed $\mathrm{B} 2+\mathrm{L}_{0}$ phases showed a higher slope than the one observed in the single $\mathrm{B} 2$ phase region. This behavior deserves further studies.

These findings show the importance of the $\mathrm{Al}$ content in the crystal structure of commercial $\mathrm{B} 2-(\mathrm{Ni}, \mathrm{Pt}) \mathrm{Al}$ bond coatings and the effect of the ternary additions on the size of the B2 unit cell (bigger intercept than for $\mathrm{NiAl}$ ).

The long-range ordering $S$ for $\mathrm{NO}$ and SFO experiments plotted in Figure 6 also exhibits a linear dependence with the $\mathrm{Al}$ content, independently of the nature of the oxidation. These results show how the $\mathrm{B} 2$ phase disorders as the $\mathrm{Al}$ is depleted during the oxidation until its transformation to the martensitic phase. The behavior of $S$ is also affected by the presence of $\mathrm{Pt}$ in the alloy due to their difference in ASF with $\mathrm{Al}$, and this affects the ordering and consequently the stability of the crystal structure, as shown before.

\section{Conclusions}

Two different isothermal oxidation experiments conducted at $1100{ }^{\circ} \mathrm{C}$ and $p \mathrm{O}_{2}=0.2 \mathrm{~atm}$, on $\mathrm{B} 2-(\mathrm{Ni}, \mathrm{Pt}) \mathrm{Al} / \mathrm{Rene} \mathrm{N} 5$ systems were performed to study the effect of chemical content on the structural stability and the martensitic phase transformation of $\mathrm{B} 2-(\mathrm{Ni}, \mathrm{Pt}) \mathrm{Al}$ bond coats. The main conclusions are presented below:

- Natural (NO) and Scale Free (SFO) Oxidation experiments allowed us to study the stability and martensitic transformation of the $\mathrm{B} 2-(\mathrm{Ni}, \mathrm{Pt}) \mathrm{Al}$ phase as a function of the composition.

- The B2 phase destabilized and transformed to martensite for NO and SFO experiments at 36.3 and 40.9 at. \% of $\mathrm{Al}, 47.7$ and 42.9 at. \% of $\mathrm{Ni}, 6.2$ and 8.5 at. \% of $\mathrm{Pt}, 4.2$ and 2.9 at. \% of $\mathrm{Cr}$ and 4.4 and 3.8 at. $\%$ of $\mathrm{Co}$, respectively.

- The lattice constant and long range ordering parameter of the $\mathrm{B} 2-(\mathrm{Ni}, \mathrm{Pt}) \mathrm{Al}$ phase have a linear dependence on the $\mathrm{Al}$ content of the coating and the slopes are similar to the binary NiAl system.

- Diffusing Cr and Co elements from the SA were identified in the bond coat and did not cause significant effects on the size and ordering of the coating.

- $\mathrm{Al}$ and Pt were found to play a determinant role in the lattice constant and $S$ of the B2 phase.

Acknowledgments: This project was funded by Conacyt FOMIX-QRO Project No. 10599 and Conacyt CIENCIA BASICA-2009 No. 130591 Projects. Authors thank D.G. Konitzer (General Electric Aircraft Engines, Cincinnati, $\mathrm{OH}$, USA), J.L. Ortiz Merino and Mike Boldrick (Peace Corps) for his support in the helpful discussion and revision of the manuscript. RA recognizes partial support of NETL through grant No. FE0008719 and JMS of the Av Humboldt foundation for the HERMES fellowship. This research has been carried out partially at CENAPROT and LIDTRA national laboratories.

Author Contributions: L.A.C.-D., H.R.-L., J.M.A.-O. and J.M.-S. conceived and designed the experiments; L.A.C.-D., J.E.G.-H., A.G.M.-G. and J.M.A.-O. performed the experiments; L.A.C.-D., J.E.G.-H., H.R.-L., J.M.A.-O. and J.M.-S. analyzed the data; G.T.-M., R.A., J.M.A.-O. and J.M.-S. contributed reagents/materials/analysis tools; J.M.-S., L.A.C.-D., H.R.-L. and J.M.A.-O. wrote the paper.

Conflicts of Interest: The authors declare no conflict of interest.

\section{References}

1. Gleeson, B.; Wang, W.; Hayashi, S.; Sordelet, D.J. Effects of Platinum on the Interdiffusion and Oxidation Behavior of Ni-Al-Based Alloys. Mater. Sci. Forum 2004, 461-464, 213-222. [CrossRef]

2. Zhang, Y.; Lee, W.Y.; Haynes, J.A.; Wright, I.G.; Cooley, K.M.; Liaw, P.K. Synthesis and cyclic oxidation behavior of a (Ni,Pt)Al coating on a desulfurized Ni-base superalloy. Metall. Mater. Trans. A 1999, 30, 2679-2687. [CrossRef]

3. Clarke, D.R.; Levi, C.G. Materials design for the next generation thermal barrier coatings. Annu. Rev. Mater. Res. 2003, 33, 383-417. [CrossRef]

4. Evans, A.G.; Clarke, D.R.; Levi, C.G. The influence of oxides on the performance of advanced gas turbines. J. Eur. Ceram. Soc. 2008, 28, 1405-1419. [CrossRef] 
5. Ansara, I.; Dupin, N.; Lukas, H.L. Thermodynamic Assessment of the Al-Ni System. J. Alloys Compd. 1997, 247, 20-30. [CrossRef]

6. Pike, L.M. Point Defect Concentrations and Hardening in Binary B2 Intermetallics. Acta Mater. 1997, 45, 3709-3719. [CrossRef]

7. Zhang, Y.; Haynes, J.A.; Lee, W.Y.; Wright, I.G.; Pint, B.A.; Cooley, K.M.; Liaw, P.K. Effects of Pt Incorporation on the Isothermal Oxidation Behavior of Chemical Vapor Deposition Aluminide Coatings. Metall. Mater. Trans. A 2001, 32A, 1727-1741. [CrossRef]

8. Jiang, C.; Besser, M.F.; Sordelet, D.J.; Gleeson, B. A combined first-principles and experimental study of the lattice site preference of Pt in B2 NiAl. Acta Mater. 2005, 53, 2101-2109. [CrossRef]

9. Bozzolo, G.; Noebe, R.D.; Honecy, F. Modeling of ternary element site substitution in NiAl. Intermetallics 2000, 8, 7-18. [CrossRef]

10. Hayashi, S.; Ford, S.I.; Young, D.J.; Sordelet, D.J.; Besser, M.F.; Gleeson, B. $\alpha-\mathrm{NiPt}(\mathrm{Al})$ and phase equilibria in the Ni-Al-Pt system at $1150{ }^{\circ} \mathrm{C}$. Acta Mater. 2005, 53, 3319-3328. [CrossRef]

11. Miracle, D.B. The Physical and Mechanical Properties of NiAl. Acta Metall. Mater. 1993, 41, 649-684. [CrossRef]

12. Jiang, C. Site preference of transition-metal elements in B2 NiAl: A comprehensive study. Acta Mater. 2007, 55, 4799-4806. [CrossRef]

13. Wang, T.; Zhu, J.; Chen, L.; Liu, Z.; Mackay, R.A. Modeling of lattice parameter in the Ni-Al system. Metall. Mater. Trans. A 2004, 35, 2313-2321. [CrossRef]

14. Meyer, R.; Entel, P. Computer simulations of martensitic transformations in NiAl alloys. Comput. Mater. Sci. 1998, 10, 10-15. [CrossRef]

15. Arroyave, R.; Shin, D.; Liu, Z.K. Ab initio thermodynamic properties of stoichiometric phases in the Ni-Al system. Acta Mater. 2005, 53, 1809-1819. [CrossRef]

16. Frank, S.; Divinski, S.V.; Södervall, U.; Herzig, C. Ni tracer diffusion in the B2-compound NiAl: Influence of temperature and composition. Acta Mater. 2001, 49, 1399-1411. [CrossRef]

17. Spitsberg, I.T.; Mumm, D.R.; Evans, A.G. On the failure mechanisms of thermal barrier coatings with diffusion aluminide bond coatings. Mater. Sci. Eng. A 2005, 394, 176-191. [CrossRef]

18. Tolpygo, V.K.; Clarke, D.R. On the rumpling mechanism in nickel-aluminide coatings part I: An experimental assessment. Acta Mater. 2004, 52, 5115-5127. [CrossRef]

19. Chen, M.W.; Livi, K.J.T.; Hemker, K.J.; Wright, P.K. Microstructural characterization of a platinum-modified diffusion aluminide bond coat for thermal barrier coatings. Metall. Mater. Trans. A 2003, 34A, 2289-2299. [CrossRef]

20. Chen, M.W.; Glynn, M.L.; Ott, R.T.; Hufnagel, T.C.; Hemker, K.J. Characterization and modeling of a martensitic transformation in a platinum modified diffusion aluminide bond coat for thermal barrier coatings. Acta Mater. 2003, 51, 4279-4294. [CrossRef]

21. Glynn, M.L.; Chen, M.W.; Ramesh, K.T.; Hemker, K.J. The Influence of a Martensitic Phase Transformation on Stress Development in Thermal Barrier Coating Systems. Metall. Mater. Trans. A 2004, 35A, 2279-2286. [CrossRef]

22. Kainuma, R.; Ohtani, H.; Ishida, K. Effect of Alloying Elements on Martensitic Transformation in the Binary NiAI ( $\beta$ ) Phase Alloys. Metall. Mater. Trans. A 1996, 27, 2445-2453. [CrossRef]

23. Yu, Z.; Hass, D.D.; Wadley, H.N.G. NiAl bond coats made by a directed vapor deposition approach. Mater. Sci. Eng. A 2005, 394, 43-52. [CrossRef]

24. Grabke, H.J. Oxidation of NiAl and FeAl. Intermetallics 1999, 7, 1153-1158. [CrossRef]

25. Brumm, M.W.; Grabke, H.J. The oxidation behaviour of NiAl-I. Phase transformations in the alumina scale during oxidation of NiAl and NiAl-Cr alloys. Corros. Sci. 1992, 33, 1677-1690. [CrossRef]

26. Bradley, A.J.; Jay, A.H. A method for deducing accurate values of the lattice spacing from X-ray powder photographs taken by the Debye-Scherrer method. Phys. Soc. 1932, 44, 563-579. [CrossRef]

27. Cullity, B.D. Elements of X-ray Diffraction, 1st ed.; Addison-Wesley: Boston, MA, USA, 1956.

28. Zhang, L.C.; Heuer, A.H. Microstructural Evolution of the Nickel Platinum-Aluminide Bond Coat on Electron-Beam Physical-Vapor Deposition Thermal-Barrier Coatings during High-Temperature Service. Metall. Mater. Trans. A 2005, 36, 43-53. [CrossRef]

29. Reed, R.C. The Superalloys Fundamentals and Applications, 1st ed.; Cambridge University Press: Cambridge, UK, 2006. 
30. Chen, M.W.; Ott, R.T.; Hufnagel, T.C.; Wright, P.K.; Hemker, K.J. Microstructural evolution of platinum modified nickel aluminide bond coat during thermal cycling. Surf. Coat. Technol. 2003, 163-164, 25-30. [CrossRef]

31. Pike, L.M.; Liu, C.T.; Anderson, I.M.; Chang, Y.A. Solute Hardening and Softening Effects in B2 Nickel Aluminides, 1998. Available online: http://www.osti.gov/scitech/biblio/676873 (accessed on 23 August 2016).

32. Del Grosso, M.F.; Mosca, H.O.; Bozzolo, G. Atomistic modeling of Pt additions to NiAl. Intermetallics 2008, 16, 1305-1309. [CrossRef]

33. Sordelet, D.J.; Besser, M.F.; Ott, R.T.; Zimmerman, B.J.; Porter, W.D.; Gleeson, B. Isothermal nature of martensite formation in Pt-modified $\beta-\mathrm{NiAl}$ alloys. Acta Mater. 2007, 55, 2433-2441. [CrossRef]

34. Jiang, C.; Sordelet, D.J.; Gleeson, B. Effects of Pt on the elastic properties of B2 NiAl: A combined first-principles and experimental study. Acta Mater. 2006, 54, 2361-2369. [CrossRef]

35. Zhang, Y.; Haynes, J.A.; Pint, B.A.; Wright, I.G.; Lee, W.Y. Martensitic transformation in CVD NiAl and (Ni,Pt)Al bond coatings. Surf. Coat. Technol. 2003, 163-164, 19-24. [CrossRef]

36. Bozzolo, G.; Amador, C.; Ferrante, J.; Noebe, R.D. Modelling of the defect structure of $\beta$-NiAl. Scr. Metall. Mater. 1995, 33, 1907-1913. [CrossRef]

(C) 2016 by the authors; licensee MDPI, Basel, Switzerland. This article is an open access article distributed under the terms and conditions of the Creative Commons Attribution (CC-BY) license (http://creativecommons.org/licenses/by/4.0/). 